\title{
Miniaturized Planar Ultra-Wideband Bandpass Filter with Notched Band
}

\author{
Xueying Guo, Yunsheng Xu, Weidong Wang \\ Key Laboratory of Wireless-Optical Communications, Chinese Academy of Sciences, School of Information \\ Science and Technology, University of Science and Technology of China, Hefei, China \\ Email: xys@ustc.edu.cn
}

Received February 2015

Copyright (C) 2015 by authors and Scientific Research Publishing Inc.

This work is licensed under the Creative Commons Attribution International License (CC BY).

http://creativecommons.org/licenses/by/4.0/

c) (i) Open Access

\begin{abstract}
This paper presents a planar ultra-wideband (UWB) bandpass filter with sharp out-of-band rejection performance. The filter is formed by a folded multiple-mode resonator to realize high performance in an operation band from 3.3 to $10 \mathrm{GHz}$ with a very compact size of $20 \mathrm{~mm} \times 20 \mathrm{~mm} \times$ $0.5 \mathrm{~mm}$. An extra notched band centered at $5.8 \mathrm{GHz}$ is further accomplished by etching a Hilbert fractal curve slit on the filter without the necessity of readjusting the geometrical parameters. The simulated and measured results are in good agreement.
\end{abstract}

\section{Keywords}

Ultra-Wideband (UWB), Bandpass Filter, Notched Band, Hilbert Fractal Curve

\section{Introduction}

Ultra-Wideband (UWB) systems have attracted increasing attention since the Federal Communications Commission released the unlicensed use of the frequency spectrum 3.1 - 10.6 GHz for UWB applications in 2002. With the rapid development of electronic products, high performance and compact size have been import issues in design considerations. The investigation on an UWB bandpass filter, which is one of the main components of UWB systems, has been a subject of interests.

Since 2005, various UWB bandpass filters have been designed and reported, including filters of composite lowpass and highpass structures [1], shorted-circuited stub filters [2] [3], multiple-mode resonator (MMR) structure filters [4], etc. Modification or improvement of MMR filters has also been proposed due to their compact size and high performance [5]-[9]. In [7] [8], the transmission zeros of MMR filters are used to realize sharp out-of-band rejection performance.

Because of the possible interference with the existing wireless local area network or other applications, the 
research on UWB bandpass filters with notched bands has also been conducted in recent years. For example, etching slots on the patch or on the ground plane [10] [11], using asymmetric coupled lines [12], and adding notch resonators [13] [14].

Based on [7], a miniaturized UWB filter formed by a MMR is realized in this paper. The MMR is formed by a stepped-impedance resonator with a stepped-impedance stub. Different from [7], however, the UWB bandpass filter here achieves UWB with a much more compact size of $20 \mathrm{~mm} \times 20 \mathrm{~mm}$ by folding the MMR. An extra notched band around $5.8 \mathrm{GHz}$ is further obtained by etching a Hilbert fractal curve slit [15] on the filter without the necessity of readjusting the geometrical parameters. The filter is fabricated on a printed circuit board with a relative permittivity of 2.65 and thickness of $0.5 \mathrm{~mm}$.

The structure of the paper is as follows. In Section 2, the configurations of the proposed filters with or without the notched band are introduced and their resonance characteristics are analyzed. In Section 3, the experiment results of the above UWB filters are presented and compared with the simulated ones. Finally, conclusions are given in Section 4.

\section{Filter Structure and Design}

\subsection{Configuration and Design}

The configuration of the proposed UWB bandpass filter without a notched band is shown in Figure 1, which consists of a folded MMR formed by a stepped-impedance resonator with widths of $W_{i}$ and lengths of $L_{i}(i=1,2$, 3 , 4). It is fed by a microstrip line with width $W$ and parallel-coupled structure with width of $W_{s}$ and lengths of $L_{s}$. This MMR structure is used to create five resonance frequencies in the passband to achieve UWB operation bandwidth by adjusting the parameters of the MMR. In addition, the stepped-impedance stub with widths of $W_{3}$ and $W_{4}$ and lengths of $L_{3}$ and $L_{4}$ can also introduce two transmission zeros, sharp rejection can then be realized by changing the locations of these transmission zeros to the edges of the passband.

Figure 2(a) shows the MMR structure. $Y_{i}$ and $\theta_{i}(i=1,2,3,4)$ are the characteristic admittances and electronic lengths, respectively. Since the MMR is symmetrical in structure, the even- and odd-mode methods can be used for its characterization. Figure 2(b) and Figure 2(c) are its even- and odd-mode equivalent circuits, respectively. The symmetrical planes are open-circuited for even-mode excitation and short-circuited for oddmode excitation. The input admittances $Y_{i n}^{e}$ and $Y_{i n}^{o}$ for the even- and odd-mode excitations can be respectively given bellow

$$
\begin{aligned}
& Y_{i n}^{e}=Y_{1}\left(Y_{1}^{e}+\mathrm{j} Y_{1} \tan \theta_{1}\right) /\left(Y_{1}+\mathrm{j} Y_{1}^{e} \tan \theta_{1}\right), \\
& Y_{i n}^{o}=j Y_{1}\left(Y_{1} \tan \theta_{1}-j Y_{2} \cot \theta_{2}\right) /\left(Y_{1}+Y_{2} \tan \theta_{1} \cot \theta_{2}\right),
\end{aligned}
$$

where

$$
\begin{aligned}
Y_{1}^{e} & =Y_{2}\left(Y_{2}^{e}+j Y_{2} \tan \theta_{2}\right) /\left(Y_{2}+j Y_{2}^{e} \tan \theta_{2}\right), \\
Y_{2}^{e} & =j Y_{3}\left(Y_{4} \tan \theta_{4}+Y_{3} \tan \theta_{3}\right) / 2\left(Y_{3}-Y_{4} \tan \theta_{3} \tan \theta_{4}\right),
\end{aligned}
$$

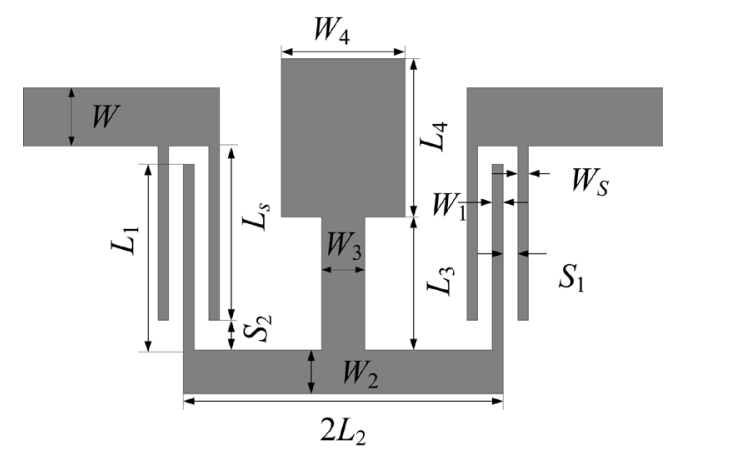

Figure 1. Configuration of the proposed UWB filter without notched band. 
From the resonance condition: $Y_{i n}^{e}=0$ or $Y_{i n}^{o}=0$, the resonance frequency of the even-mode $f_{e}$ or that of the odd-mode $f_{o}$ can be obtained from

$$
\frac{k_{2}-k_{1} k_{2} \tan \theta_{1} \tan \theta_{2}}{2\left(\tan \theta_{3} \tan \theta_{4}-k_{3}\right)}=\frac{k_{1} \tan \theta_{1}+\tan \theta_{2}}{\tan \theta_{4}+k_{3} \tan \theta_{3}},
$$

or

$$
k_{1} \tan \theta_{1} \tan \theta_{2}=1 \text {, }
$$

where $k_{1}=Y_{1} / Y_{2}, k_{2}=Y_{3} / Y_{2}$, and $k_{3}=Y_{3} / Y_{4}$. The transmission zeros $f_{z}$ can be produced by $Y_{\text {in }}^{e}=Y_{\text {in }}^{o}$.

Three $f_{e}\left(f_{e 1}, f_{e 2}, f_{e 3}\right)$, two $f_{o}\left(f_{o 1}, f_{o 2}\right)$, and two $f_{z}\left(f_{z 1}, f_{z 2}\right)$ can be determined within the passband. To realize sharp rejection, the locations of the transmission zeros $f_{z}$ can be moved to the edges of the passband by adjusting $k_{3}, L_{3}$, and $L_{4}$. The resonance frequencies $f_{o}$ can be changed by adjusting $k_{1}, L_{1}$, and $L_{2}$ and those of $f_{e}$ by $k_{1}, k_{2}$, and $k_{3}$, and $L_{i}(i=1,2,3,4)$. Figure 3 plots the resonance frequencies and transmission zeros of the MMR with varying $k_{1}, k_{2}$, and $k_{3}$. It is seen that $f_{e}$ and $f_{z}$ can be very close at both lower and upper frequencies, such that sharp rejection can be realized at the band edges.

The parameters $W_{s}$ and $S_{1}$ determine the coupling of the MMR and parallel-coupled structures. Figure 4 illustrates the $\left|S_{21}\right|$ simulated by HFSS with weak and strong coupling. From the weak coupling the resonance frequencies and transmission zeros can be obviously observed. With strong coupling and the MMR characteristics, an UWB bandpass filter with high performance can be realized.

\subsection{UWB Filter with Notched Band}

Since a Hilbert fractal curve slit can produce a narrow notched band without increasing circuit area [15], it's utilized and etched on the stepped-impedance stub to produce a notched band around $5.8 \mathrm{GHz}$, while the other structure parameters remain unchanged, as shown in Figure 5. Figure 6 depicts the change of resonant frequencies with different values of $x_{h}, y_{h}$ or $w_{h}$. By fine-tuning the dimensions of the Hilbert fractal curve slit, the

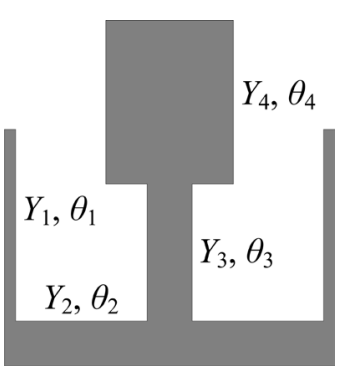

(a)

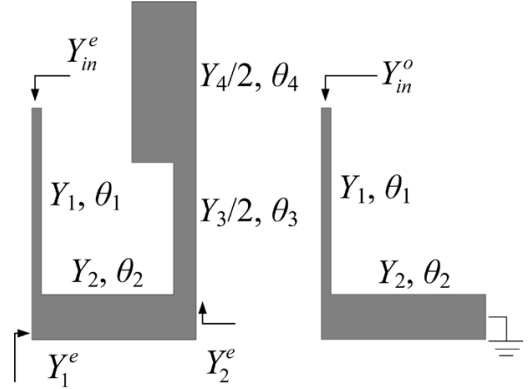

(b) (c)

Figure 2. (a) Configuration of MMR; (b) Even-mode equivalent circuit; (c) Odd-mode equivalent circuit.

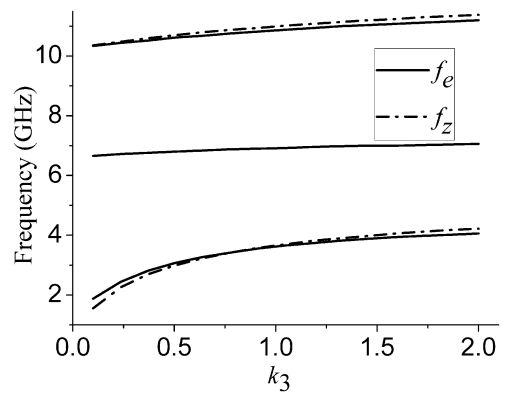

(a)

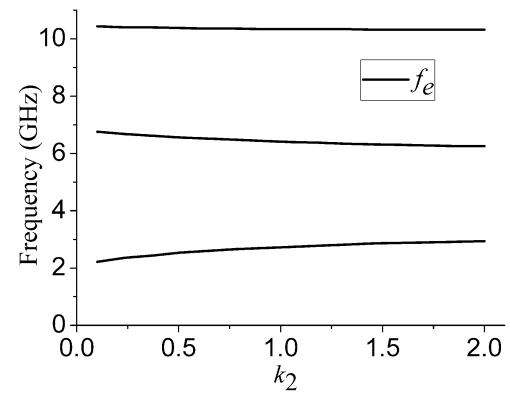

(b)

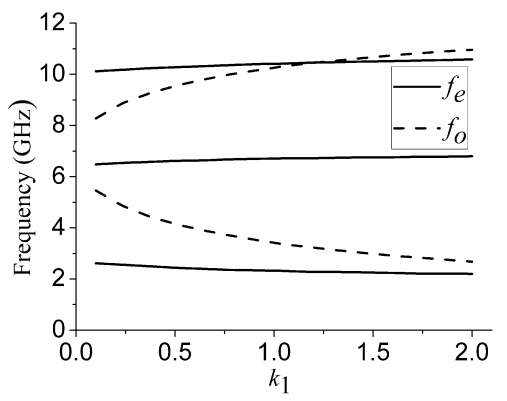

(c)

Figure 3. Resonace characteristics of MMR. (a) With varying $k_{3}$. $k_{1}=1, k_{2}=0.2$; (b) With varying $k_{2} \cdot k_{1}=1, k_{3}=0.2$; (c) With varying $k_{1} . k_{2}=0.2, k_{3}=0.2 . L_{1}=8 \mathrm{~mm}, L_{2}=7 \mathrm{~mm}, L_{3}=10 \mathrm{~mm}$, and $L_{4}=4 \mathrm{~mm}$. 


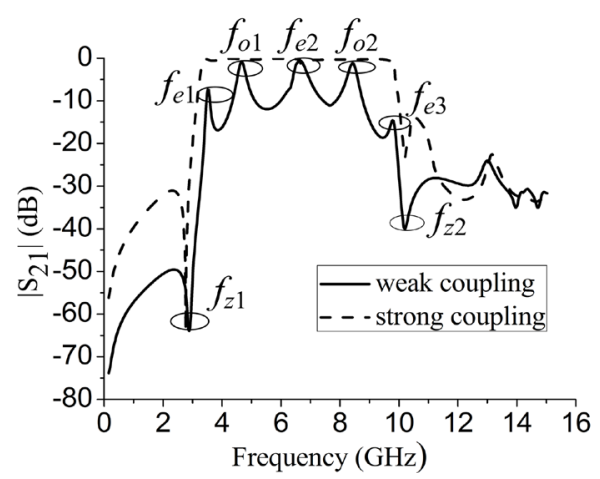

Figure 4. Simulated $\left|S_{21}\right|$ with weak and strong coupling.

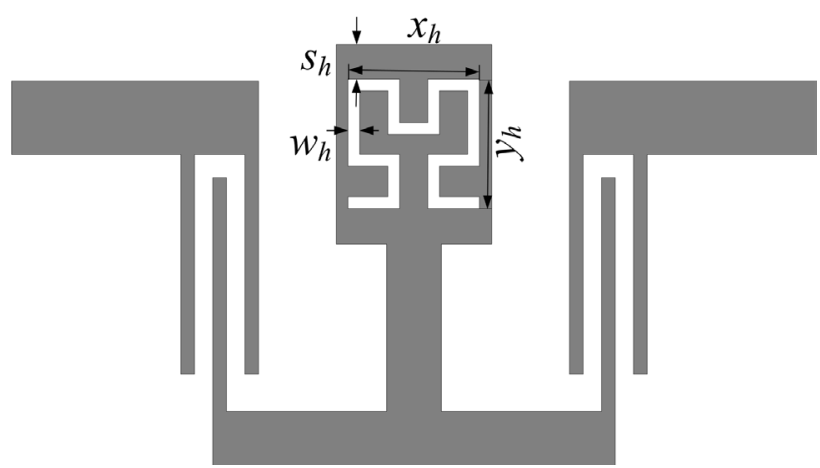

Figure 5. Configuration of the filter with notched band.

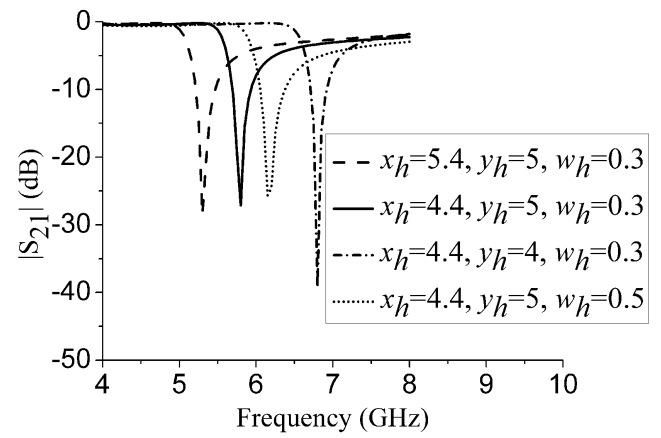

Figure 6. Simulated $\left|S_{21}\right|$ of the notched band.

notched band can be obtained in the desired frequency range.

\section{Experiment Results and Discussions}

The proposed filters with or without a narrow notched band are fabricated, as shown in Figure 7, and measured to demonstrate their performance. A SMA connector is attached to the $50 \mathrm{ohm}$ microstrip feeding line of $W=$ $1.35 \mathrm{~mm}$. SMA connectors are included in the simulation model. The overall sizes of the filters are $20 \mathrm{~mm} \times 20$ $\mathrm{mm}$. The simulation shows that the dimensions of the metallic boxes have little influence on the performance. The structure parameters are: $W_{1}=0.2, W_{2}=1.925, W_{3}=2.25, W_{4}=6, W_{s}=0.18, L_{s}=L_{1}=7.8, L_{2}=6.75, L_{3}=$ 6.1, $L_{4}=7, S_{1}=0.1$, and $S_{2}=0.2$.

Figure 8 illustrates the simulated and measured results of the UWB bandpass filter without a notched band. The measured pass band is from $3.3 \mathrm{GHz}$ to $10 \mathrm{GHz}$ with a return loss less than $-10 \mathrm{~dB}$.

Figure 9 depicts the simulated and measured results of the UWB bandpass filter with a narrow notched band. The design parameters for the notch are: $x_{h}=4.4, y_{h}=5, w_{h}=0.3$, and $s_{h}=2$. It has a measured notched band 


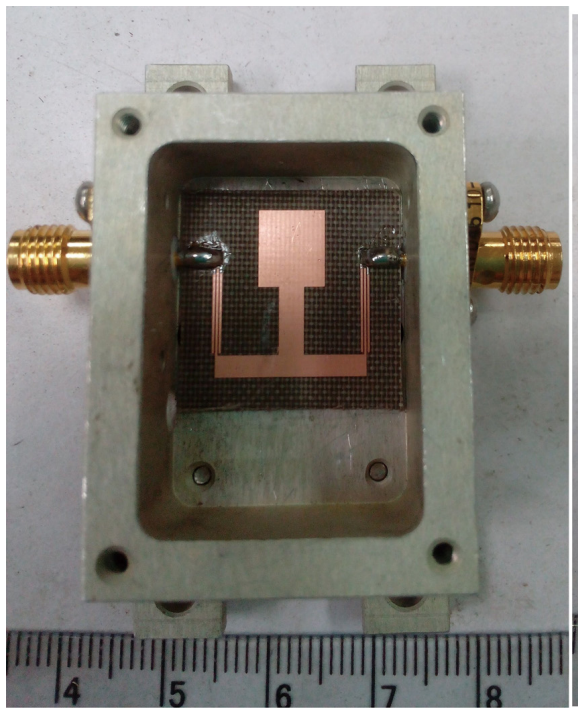

(a)

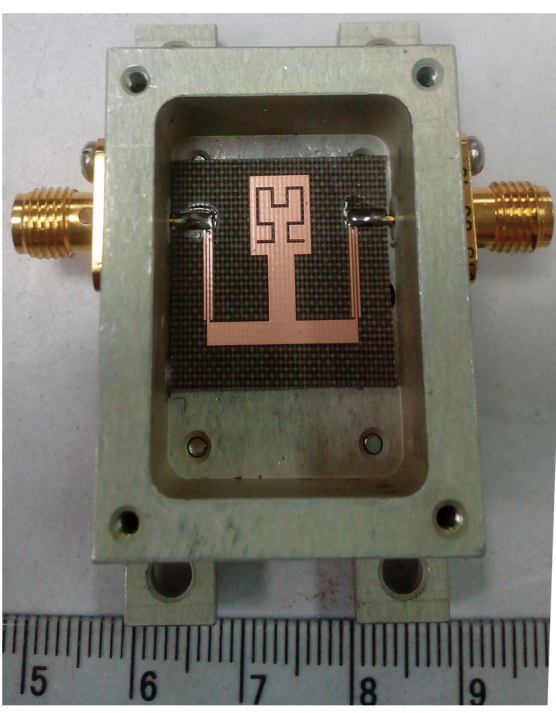

(b)

Figure 7. Photographs of the filters. (a) Without a notched band; (b) With a notched band.

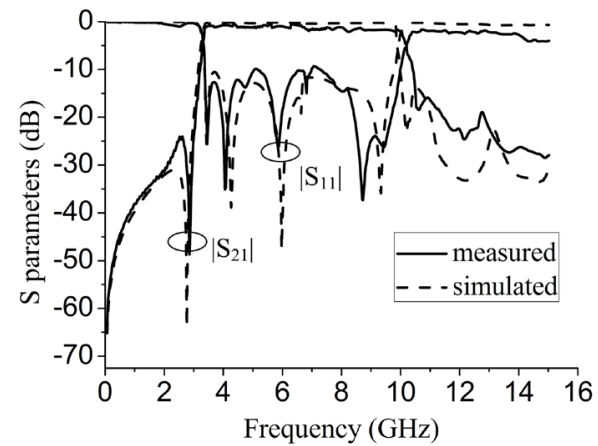

Figure 8. Simulated and measured S parameters of the proposed UWB filter without notched band.

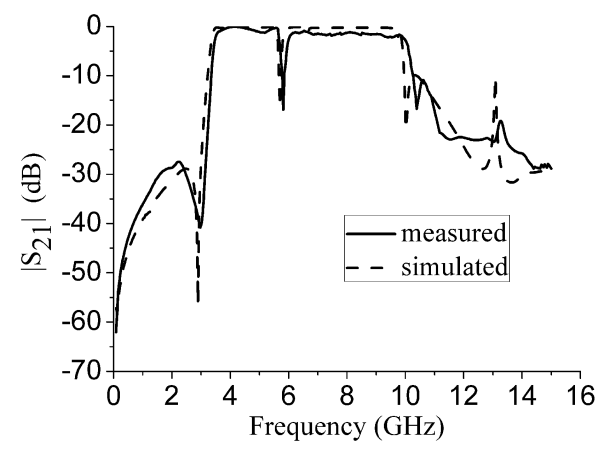

(a)

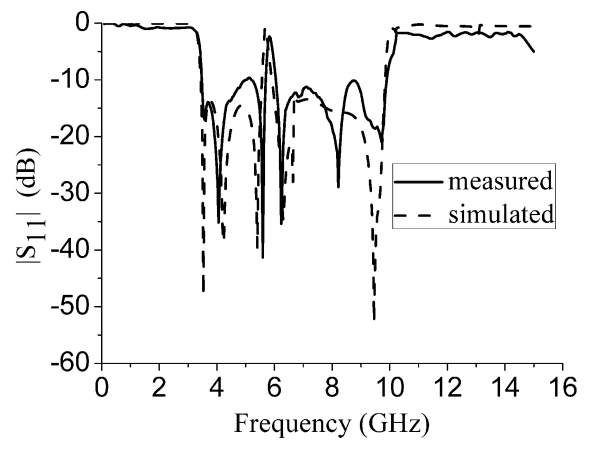

(b)

Figure 9. Simulated and measured S parameters of the filter with a notched band (a) $\left|S_{21}\right|$; (b) $\left|S_{11}\right|$.

from $5.7 \mathrm{GHz}$ to $6.0 \mathrm{GHz}$ and the attenuation is less than $-15 \mathrm{~dB}$ at the center frequency. The deviations of the measurements from the simulations may be attributed to tolerance in the fabrication process and diversity of material parameters. 


\section{Conclusion}

In this paper, very compact UWB bandpass filters with or without a narrow notched band are designed and realized. The fabricated filters have a wide passband from $3.3 \mathrm{GHz}$ to $10 \mathrm{GHz}$ with sharp rejection at the band edges. A Hilbert fractal curve slit is etched on the stepped-impedance stub to obtain the notched band around 5.8 $\mathrm{GHz}$ without increasing the circuit area. With good frequency performances and compact sizes, the proposed filters are attractive to UWB applications.

\section{Acknowledgements}

This work was supported by the National High-Tech R \& D Program (863 Program) under Grant 2011AA010201 and the Key Technologies R \& D Program under Grant 2015ZX03002002..

\section{References}

[1] Hsu, C.-L., Hsu, F.-C. and Kuo, J.-T. (2005) Microstrip Bandpass Filters for Ultra-Wideband (UWB) Wireless Communications. IEEE MTT-S International Microwave Symposium Digest, 679-682. http://dx.doi.org/10.1109/MWSYM.2005.1516698

[2] Hong, J.-S. and Shaman, H. (2005) An Optimum Ultra-Wide-Band Microstrip Filter. Microwave and Optical Technology Letters, 47, 230-233. http://dx.doi.org/10.1002/mop.21133

[3] Li, X. and Ji, X. (2014) Novel Compact UWB Bandpass Filters Design with Cross-Coupling between Short-Circuited Stubs. IEEE Microwave Theory and Wireless Component Letters, 24, 23-25. http://dx.doi.org/10.1109/LMWC.2013.2287231

[4] Zhu, L., Sun, S. and Menzel, W. (2005) Ultra-Wideband (UWB) Bandpass Filters Using Multiple-Mode Resonator. IEEE Microwave Theory and Wireless Component Letters, 15, 796-798. http://dx.doi.org/10.1109/LMWC.2005.859011

[5] Yao, B., Zhou, Y., Cao, Q. and Chen, Y. (2009) Compact UWB Bandpass Filter with Improved Upper-Stopband Performance. IEEE Microwave Theory and Wireless Component Letters, 19, $27-29$. http://dx.doi.org/10.1109/LMWC.2008.2008558

[6] Song, K. and Xue, Q. (2010) Inductance-Loaded Y-Shaped Resonators and Their Applications to Filters. IEEE Transactions on Microwave Theory and Techniques, 58, 978-984. http://dx.doi.org/10.1109/TMTT.2010.2042509

[7] Chu, Q.-X. and Tian, X.-K. (2010) Design of UWB Bandpass Filter Using Stepped-Impedance Stub-Loaded Resonator. IEEE Microwave Theory and Wireless Component Letters, 20, 501-503. http://dx.doi.org/10.1109/LMWC.2010.2053024

[8] Zhu, H. and Chu, Q.-X. (2013) Compact Ultra-Wideband (UWB) Bandpass Filter Using Dual-Stub-Loaded Resonator (DSLR). IEEE Microwave Theory and Wireless Component Letters, 23, 527-529. http://dx.doi.org/10.1109/LMWC.2013.2278278

[9] Ahmed, K.U. and Virdee, B.S. (2013) Ultra-Wideband Bandpass Filter Based on Composite Right/Left Handed Transmission-Line Unit-Cell. IEEE Transactions on Microwave Theory and Techniques, 61, 782-788.

[10] Yang, G.-M., Jin, R., Vittoria, C., Harris, V.G. and Sun, N.X. (2008) Small Ultra-Wideband (UWB) Bandpass Filter with Notched Band. IEEE Microwave Theory and Wireless Component Letters, 18, 176-178. http://dx.doi.org/10.1109/LMWC.2008.916781

[11] Luo, X., Ma, J.-G., Yeo, K.S. and Li, E.-P. (2011) Compact Ultra-Wideband (UWB) Bandpass Filter with Ultra-Narrow Dual- and Quad-Notched Bands. IEEE Transactions on Microwave Theory and Techniques, 59, 1509-1519. http://dx.doi.org/10.1109/TMTT.2011.2116800

[12] Shaman, H. and Hong, J.S. (2007) Asymmetric Parallel-Coupled Lines for Notch Implementation in UWB Filters. IEEE Microwave Theory and Wireless Component Letters, 17, 516-518. http://dx.doi.org/10.1109/LMWC.2007.899314

[13] Zhu, H. and Chu, Q.-X. (2013) Ultra-wideband Bandpass Filter with A Notch Band Using Stub-Loaded Ring Resonator. IEEE Microwave and Wireless Components Letters, 23, 341-343. http://dx.doi.org/10.1109/LMWC.2013.2262928

[14] Zhao, J., Wang, J., Zhang, G. and Lin, J.-L. (2013) Compact UWB Bandpass Filter with Dual Notched Bands Using E-Shaped Resonator. IEEE Microwave and Wireless Components Letters, 23, 638-640. http://dx.doi.org/10.1109/LMWC.2013.2283873

[15] Yan, Z.-M., Xu, Y.-S. and Wang, W.-D. (2012) Miniaturized Ultra-Wideband Slot Antenna with Dual Band-Notches and Eliminating Spurious Stop Band. Progress in Electromagnetics Research C, 30, 119-130.

http://dx.doi.org/10.2528/PIERC12040310 